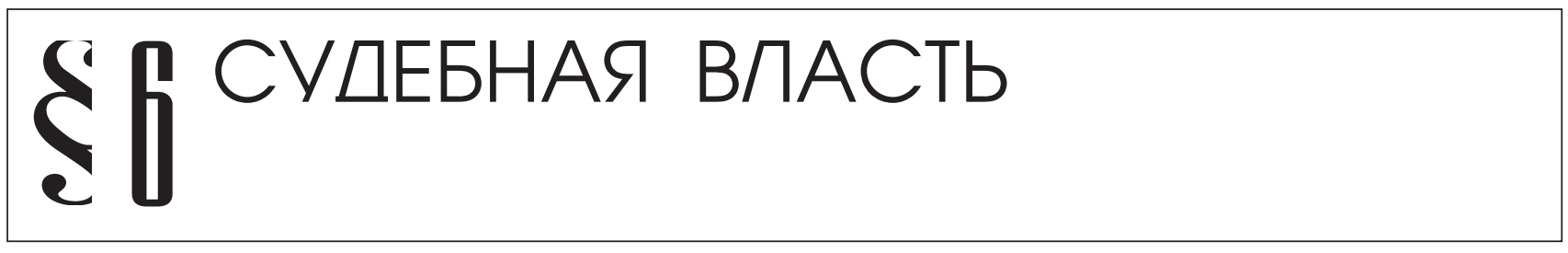

Рёрихт A.A.

\title{
ИНСТИТУТ НЕЗАВИСИМОСТИ СУДЕЙ В РОССИЙСКОЙ ПРАВОВОЙ ДОКТРИНЕ: ОПРЕДЕЛЕНИЕ ПОНЯТИЙ, ФУНКЦИЙ, СТАТУСА И МЕСТА В ПРАВОВОЙ СИСТЕМЕ
}

\begin{abstract}
Аннотация: В статье указываются цели и содержание правовой конструкиии «независимость судебной власти/суда/судей», признаваемой самостоятельным правовым институтом, определяются исходные понятия и перечисляются субъекты судебной независимости, то есть судебная власть, суд и судьи, определяется их статус и значение по Конституции РФ и федеральному законодательству. Отдельно анализируется понятие независимости по российской и немеикой доктрине, а также понятие «независимость судей», «независимость судебной власти». Дается классификаџия норм, регулирующих независимость судей. Предлагается ввести в оборот (научный, в первую очередь) понятие «зона независимости судей» и раскрывается его содержание, значение и перспективы использования для сравнительно-правовых исследований и для совершенствования российского законодательства. Используется сравнительно-правовой метод анализа в рамках которого вопросы независимости судей изучаются как в России, так и в ФРГ. В сравнительном ключе, исследуются и теоретические аспекть независимости судей, суда и судебной власти.
\end{abstract}

Ключевые слова: Право, суд, судьи, независимость, гарантии, правовой институт, судебная власть, Россия, сопоставление предписаний, процессуальное право.

Abstract: The article states the goals and content of the legal construct of "independence of the judicial authority/court/ judges" recognized as an independent legal institution. The author defines the original concepts, and lists the subjects of judicial independence, i.e. the judicial authority, courts and judges, determines their status and influence according to the Constitution of the Russian Federation and federal legislation. A separate analysis is conducted on the concept of independence by the Russian and German doctrines, as well as the notions of "independence of the judiciary", and "independence of judicial authority". The article gives the classification of the norms that regulate the independence of the judiciary. The author proposes to introduce into discourse (first and foremost into scientific) the notion of "the zone of independence of the judiciary" and explains its content, meaning, and prospects for implementation in legal comparative research and improvements to the Russian legislation.

Keywords: Law, Court, Judge, Independence, Guarantees, Legal institution, Judicial authority, Russia, Comparison of regulations, Procedural law.

\section{Цели использования конструкции «институт независимости судей».}

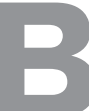

теории российского права, а для ее оценки полезно, на наш взгляд, использовать и подходы, выработанные в немецком праве, раскрытие смысла предписаний закона осуществляется на основе некоторой традиции. Сопоставление предписаний о дозволенном и запрещенном (Gebote - Verbote) возможно только:

a) на основе принятого значения;

б) с учетом их связи между собой; в) в определенном правовом контексте.

Применительно к независимости судей эти условия особенно важны. Не ясно или не до конца ясно понятие независимости, и оно раскрывается только вначале в контексте конституционного, затем - судоустройственного, затем - процессуального права. В значимых ситуациях на практике имеют различное значение (противоположные независимости по содержанию) глаголы «подчинен» («подчиняются») и «unterworfen», и их невозможно понять без использования конструкций толкования, аналогии, судейского усмотрения, судебной практики (Richterrecht). 
Конструкция института судебной независимости основана одновременно на системном подходе и на логике. Она позволяет создавать и использовать общий язык правовых коммуникаций. Соответственно, она позволяет понять значение судебной независимости в российском правовом контексте.

В данном случае в интересах дальнейшего сравнительно-правового исследования даются:

а) толкование понятий, используемых в российской юридической литературе, что необходимо для их сопоставления с понятиями немецкого права;

б) описание существующих в литературе подходов к характеристике судебной независимости как целостного явления и восполняющих пробелы закона;

в) содержание и структура института.

При этом выявляются особенности понимания судебной независимости в российской теории права.

\section{Исходные понятия в структуре проблемы.}

В юридическом языке Российской Федерации используется несколько понятий, сопоставимых с понятием независимости судей. Они подлежат специальному анализу в целом и $a d h o c$, т.е. применительно к отдельным ситуациям, но до этого с учетом языковых различий следует дать им хотя бы самые общие дефиниции. Исходные понятия в немецком праве даны в Комментариях к Основному закону (преимущественно к ст. 92, 97 и другим).

К исходным относятся в РФ понятия: «независимость судебной власти», «независимость судебных решений», «независимость суда» и «независимость судей». Они близки друг к другу, но все различаются между собой. Оттенки смысла этих понятийных оборотов проявляются следующим образом.

\section{Субъекты судебной независимости.}

Судебная власть, судьи и суд. Эти понятия употребляются в законодательных текстах. Смысловые различия между ними основываются на характере определения места судебной власти в Конституции РФ. Статья 10 Конституции РФ, в которой провозглашается принцип разделения властей и устанавливается самостоятельность органов законодательной, исполнительной и судебной власти, содержится в Разделе первом в главе 1 «Основы конституционного строя». Она определяет в качестве носителей институты судебной власти и судебную власть как ветвь разделения властей.
Понятие судов отсутствует в Конституции РФ, но множество ее статей, в которых суды упоминаются, позволяет четко определять их конституционное положение и соотношение с судебной властью. Термин «судебная власть» впервые в России появился как легитимный в пункте 13 «Декларации о государственном суверенитете РСФСР» от 12 июня 1990 г. и принцип разделения властей был «впервые, как отмечает И.Б. Михайловская, введен Конституцией 1993 г.»’ . Возможно, поэтому в литературе отсутствует согласие в понимании судебной власти, и она рассматривается либо как система органов, либо как система функций, что больше соответствует части 2 ст. 118 Конституции РФ² .

Положение судей в структуре судебной власти определяется также рядом статей, из которых важнейшими являются статья 119 и часть 1 ст. 120 Конституции РФ, в которой прямо провозглашается: «Судьи независимы и подчиняются только Конституции Российской Федерации и федеральному закону» и которая содержится в главе 7 «Судебная власть» Раздела 1 и определяет в качестве носителей независимости судей.

В российской и до этого в советской правовой литературе указанная иерархия понятий имеет смысловое значение, поскольку в ней особенно часто делались попытки (М.С.Строгович и В.М.Савицкий ${ }^{3}$, Т.Г. Морщакова ${ }^{4}$, И.Л.Петрухин ${ }^{5}$ , позже Е.Б. Абросимова ${ }^{6}$ и др.7 ) создания особой правовой отрасли, именуемой «Судебная власть». Как научная дисциплина «Судебная власть» должна была объединять в себе общие проблемы функционирования судов, уголовный и гражданский, а затем и арбитражный процессы. Представители этого направления обычно занимали, насколько это было возможно, либеральные позиции и, тем самым, использование в различных ситуациях по-

\footnotetext{
${ }^{1}$ Судебная власть. С.20 Под ред. И.Л. Петрухина. М.: ТК Велби, Проспект, 2003.

${ }^{2}$ Там же. С. 21 и след.

${ }^{3}$ См.: Строгинович М.С. Курс советского уголовного процесса. М.: Изд-ва АН СССР, 1958. С. 111 и след.

${ }^{4}$ См.: Савицкий В.M. Организация судебной власти в Российской Федерации. Учебное пособие. М. Бек, 1996.

${ }^{5}$ Судебная власть. С.20 Под ред. И.Л. Петрухина. М.: ТК Велби, Проспект, 2003.

${ }^{6}$ См.: Абросимова Е.А. Судебная власть в Российской Федерации: системы и принципы. М., 2002

${ }^{7}$ См., например: Лазарева В.А. Судебная власть и ее реализация в уголовном процессе. Самара, 1999; Ржевский В.А., Чепурнова Н.М. Судебная власть в Российской Федерации: конституционные основы организации и деятельности. М., 1998.
} 
DOI: $10.7256 / 1811-9018.2015 .5 .13917$

При цитировании этой статьи сноска на dоі обязательна

\section{Право и политика 5 (185) • 2015}

нятия «судебная власть» имело определенное идентифицирующее значение, подчеркивая ее независимость как одной из властей. «Судебная власть, - как писал И.Л. Петрухин в предисловии к одноименной коллективной монографии, - есть независимая и самостоятельная ветвь государственной власти, которая на основе права разрешает социальные конфликты, следит за соответствием нормативных и правоприменительных актов Конституции РФ и законам, а также устанавливает юридически значимые факты» ${ }^{8}$.

В то же время понятие независимости судей имеет субъектный характер и больше связывается с их статусом, компетенциями и условиями соблюдения независимости.

Понятие независимости судебных решений, т.е. итога деятельности суда и судей, в российской литературе также приобретает самостоятельный смысловой оттенок; он в основном соотносится с процессуальным правом.

Так, в фундаментальной работе Г.А.Сатарова, В.Л.Римского, Ю.Н. Благовещенского «Социологическое исследование российской судебной власти» ${ }^{9}$, в которой описываются результаты изучения правосознания граждан и предпринимателей по соответствующей проблематике, раздельно приведены результаты исследования поддержки независимости судебных решений и судебной власти на макро и микроуровнях. Выявленные авторами различия заслуживают отдельного обсуждения.

\section{Содержание понятия «независимость».}

Независимость - это центральное понятие; оно должно рассматриваться как часть общего русского и немецкого языка и как профессиональный правовой термин, приобретающий различные смыслы в зависимости от контекста. В российской юридической литературе, как и в литературе немецкой, это понятие раскрывается традиционно и, как кажется, недостаточно полно.

Обращаясь к проблематике независимости судебной власти или судей, российские авторы, так или иначе, выделяют независимость в институциональном аспекте, и понимают под ней независимость судов и судей от иных органов, или самостоятельность, т.е.

\footnotetext{
${ }^{8}$ Судебная власть. С.7.

${ }^{9}$ Сатаров Г.А., Римский В.Л., Благовещенский Ю.Н. «Социологическое исследование российской судебной власти»
}

от кого-то вовне, а также независимость ее носителей изнутри, т.е. как беспристрастность. Вероятно, можно полагать, что этому с определенными особенностями соответствуют понятия личностной (persönliche) и материальной независимости (sachliche Unabhängigkeit), используемые немецким правом.

Однако необходимо иметь в виду, что в русском языке слово «независимость» рассматривается как состояние и одновременно как качество. Первое значение - независимость от кого-то или чего-то - отражает наличие возможностей и ограничение возможностей, т.е. свободу выбора. Второе значение - независимость в чем - отражает предмет независимости, например, независимость при принятии определенных решений. Сочетание значений определяет статусные характеристики, прежде всего, место в социальной структуре, иерархии, например, «независимость крестьян». Точно также понятие «независимость судей» выделяет их, к примеру, из иных государственных служащих.

Понятие «подчиняются» в российском законодательстве нужно рассматривать как недостаточно определенное. Подчиняться - значит - принудительно, т.е. независимо от своего желания, согласовывать свое поведение с некоторыми стандартами (распоряжением, социальной, собственно правовой нормой). Но в праве, как известно, подчинять свое поведение закону крайне сложный процесс, предполагающий соблюдение многих условий.

Немецкий словарь Крайфельдса определяет независимость судьи ( Unabhängigkeit des Richters), отсылая к ст. 97 абз.1 пар. 25 Закона о судьях ФРГ, скорее, как качество и состояние ${ }^{10}$. В Комментарии к Основному закону проф. Хельмут Шульце-Фелитц сопоставляет независимость судей с кирпичиком в архитектуре правового государства ${ }^{11}$. В учебниках по немецкому государственному праву она рассматривается как особенность судебной деятельности.

Таким образом, при сравнительном анализе института судебной независимости в РФ и ФРГ необходимо уделять особое внимание проблематике перевода отдельных понятий, всякий раз определяя, о чьей и какой независимости говорится в определенном контексте. Это в русской литературе может быть независимость судебной власти, суда, судей (их различных категорий), судебных решений.

\footnotetext{
${ }^{10}$ Creifeids. Rechtsworterbuch. 17 Aufl. Munchen: C.H. Beck, 2002. S. 1399-1400.

${ }^{11}$ Schulze-Fielitz, Kommentar zum GG, Munchen: C.H. Beck, 2004. S. 487.
} 
Независимость выраженно, в прямых словесных формулировках, понимается как независимость от различных внешних и внутренних факторов, т.е. как система гарантий, и, менее ясно - как предмет независимости, независимость в чем-то, свобода в осуществлении данной группы обязанностей и прав.

Выделение второго значения независимости судебной власти, суда, судей, судебных решений необходимо, ибо:

а) независимость не может быть беспредельной;

б) нарушение ее границ опасно для общества.

\section{Независимость судей как институт судебного права.}

Для российского правопонимания рассмотрение группы правовых норм имеет самостоятельный смысл. В отечественной юридической литературе, особенно в работах по общей теории права, обычно уделяется существенное внимание структурированию права, классификации и анализу его элементов. Выполнено много работ, раскрывающих понятия института права, принципа ${ }^{12}$. Одной из наиболее авторитетных работ в российском правоведении является написанная С.С.Алексеевым книга «Общая теория права» ${ }^{13}$, В 2010 г. вышел в свет составленный проф. В.М.Барановым ретроспективный библиографический указатель «Техника правотворчества. Природа. Основные приемы. Значение» объемом 659 стр. ${ }^{14}$. Здесь десятки страниц занимает перечень публикаций о принципах права, правовых презумпциях, символах, фикциях, преюдиции и пр.

В работах этих исследователей обосновывается взгляд, по которому признание группы правовых норм тем или иным элементом права определяет и предмет ее исследования, и ее место в иерархии права, а на этой основе - цели, функции и возможности в структуре правовой системы. В этой традиции признание независимости институтом права или правовой деятельности действительно определяет его связи с иными правовыми нормами и иными институтами. Кроме того, выделение и особое рассмотрение независимости судебной власти позволяет совместно рассматривать

${ }^{12}$ См., например: Общая теория государства и права. В трех томах / Под ред. М.Н. Марченко. Изд. М.: ЗЕРЦАЛО, 2002. С. 75-86, 332-348; Явич Л.С. Общая теория права. Л.: изд. ЛГУ, 1976. С. 149-159 и многие др.

${ }^{13}$ См.: Алексеев C.С. Общая теория права. М.: Проспект, 2008.

${ }^{14}$ См.: Баранов В.М. Техника правотворчества. Природа. Основные приемы. Значение. М.: Юнити-Дана, Закон и право, 2010. реально существующий круг норм о независимости как благе и независимости как угрозе.

Независимость судей в российской литературе преимущественно рассматривается как условие функционирования судебной власти, либо как принцип. Так, В.М. Савицкий начал комментировать статью 120 Конституции РФ словами: «1. Независимость судей - главное условие существования в стране самостоятельной и авторитетной судебной власти, способной объективно и беспристрастно осуществлять правосудие, защищать права и законные интересы граждан» ${ }^{15}$.

Все же в российской литературе, прежде всего, конституционно-правовой, соотносясь с судами и судьями, независимость судебной власти определяется преимущественно как принцип организации и деятельности судебной власти. По многократно повторяемому в российской литературе мнению, независимость судебной власти «является отправным принципом, определяющим положение суда в современном государстве» ${ }^{16}$. Но содержательно признание независимости только принципом судебной власти для сравнительного исследования оказывается правильным, но недостаточным. Действительно, в некотором противоречии с характеристикой принципа в общей теории права, где рассматривается преимущественно его регулятивное действие, специалисты в области конституционного и судебного права выходят за пределы анализа принципа как правовой конструкции и закрепления (см. выше) в различных отраслях права. Они исследуют широкий круг норм, относящихся к независимости, которые включают в себя нормы, программирующие и ограничивающие деятельность судебной власти, суда, судьи. Отсюда необходимость сравнивать, как общество защищает суд и как оно защищается от него ${ }^{17}$. Таким образом, получение адекватного представления о судебной независимости в РФ требует рассмотрения ее как особого правового института.

Независимость судебной власти представляет собой самостоятельный правовой институт, содержащий в

\footnotetext{
${ }^{15}$ Конституция Российской Федерации. Научно-практический комментарий / Под ред. акад. Б.Н. Топорнинв. М.: Юристъ, 1997. С. 603. См. также: Комментарий к Конституции Российской Федерации / Под общей ред. В.В. Лазарева. 3-е изд. М.: Новая правовая культура, 2009; М.: проспект, 2009.

${ }^{16}$ Горбуз А.К., Краснов М.А., Мишина Е.А., Сатаров Г.А. Указ. соч. С. 225 .

${ }^{17}$ Возможный и реальный произвол суда, злоупотребления судей вызывает еще большее беспокойство людей, чем давление на суд, хотя бы потому, что нарушения независимости судей обычно более скрытны.
} 


\section{Право и политика 5 (185) 2015}

себе предписания различного уровня, регулирующий судебную деятельность, включая нормы о признании независимости принципом. Подобно уголовному или иному процессу в целом институт независимости ${ }^{18}$ одновременно включает в себя нормы, устанавливающие порядок деятельности, которая в данном случае выражена, на первый взгляд, преимущественно через запреты недозволенного поведения.

На собственно институциональном уровне независимость находит свое выражение в нормах Конституции РФ о разделении властей, в правовой регламентации системы судебной власти и ее отраслей, что предполагает ее самостоятельное организационное, кадровое, финансовое и иное обеспечение, в отдельных процессуальных порядках.

На содержательном уровне, также по господствующему в российской литературе мнению, независимость судебной власти чаще описывается как недопущение незаконного влияния или давления на судей. Это проявляется в особых порядках их отбора, т.е. допуска к деятельности в качестве судей, затем приостановления и прекращения полномочий, запрещении незаконных указаний судьям, обеспечении неприкосновенности и безопасности судей, ресурсном обеспечении функционирования судебной системы. Однако, и это требует нормативной регламентации, т.е. включения соответствующих норм в институт ${ }^{19}$.

Таким образом, институт независимости судей рассматривается далее как некоторая совокупность норм, содержащихся в Конституции РФ и отраслевом законодательстве. Для российской правовой теории это означает необходимость отбора всех или важнейших норм, так или иначе влияющих на содержание и реализацию независимости судей; установление связей

${ }^{18}$ См.: Строгинович М.С. Курс советского уголовного процесса. М.: АН СССР, 1058. С.74 и след.

${ }^{19}$ Разумеется, существуют и иные понятийные обороты, характеризующие институциональную и содержательную независимость суда и судей. Это связано с острой полемикой о реальном состоянии независимости суда и судей, механизмах ее осуществления. В последнее время в обсуждении проблематики судебной независимости принимают самое активное участие представители иных специальностей, а так же в широких масштабах журналисты и блогеры.

При этом предметом полемики у непрофессионалов преимущественно является процесс осуществления независимости, а не ее провозглашения. Разумеется, это связано с общей неудовлетворенностью положением дел на практике, недоверием граждан к возможности обеспечения независимости в суде. Как и повсюду, многие гарантии независимости суда и судей деформируются под влиянием внутренних, в частности организационных и личностных, факторов судебной деятельности и внешнего давления. между ними, их иерархии, выявление пробелов права; обнаружение и разрешение конкуренции правовых норм. В немецком праве конструкция правового института, вероятно, излишняя, хотя нынче входящая также в моду. В российском праве она традиционно рассматривается как элемент юридической техники.

С этих позиций правовой институт независимости судей устанавливает связи между статьями 10, 120 Конституции РФ, нормами о наделении статусом судьи и профессиональной карьере судей, о судебных иммунитетах, гарантиях осуществления профессии судьи, процессуальных порядках осуществления правосудия (доказывание, ведение судебных заседаний, прием граждан, тайна совещательной комнаты и др.), порядках изменения (отмены) решений судьи, ограничении участия в политической и процессуальной деятельности.

По другой классификации институт независимости судей включает в себя:

a) нормы о компетенции судей, определяющие пределы их независимости, различающейся по должностному положению судьи, выполняемым процессуальным обязанностям, установленным на основе судоустройственного и процессуального законодательства (как уже отмечалось, независимость судьи в уголовном процессе шире, чем в гражданском; в сфере общего права она шире, чем в сфере континентального права);

б) нормы об отдельных обязанностях а также о материально-правовых и процессуальных процедурах; судья обязан считаться с вердиктом присяжных заседателей, обязан соблюдать принцип non bis in idem, соблюдать нормы о действии закона во времени и пространстве;

в) нормы о праве судей на усмотрение при принятии решений; апробированные методики толкования закона;

г) нормы об условиях отправления правосудия;

д) нормы о гарантиях от недозволенного влияния со стороны легислативы, экзекутивы, юдикативы;

е) нормы о гарантиях против воздействия на карьеру судьи и его личность, включая уголовно-правовые запреты (преступления против правосудия).

Такое построение института независимости судей позволяет обнаружить, классифицировать и определить значение множества факторов, определяющих состояние независимости судей.

\section{Позитивная сторона феномена независимости судей.}

Она раскрывается понятием «подчинение закону». Об этом по-существу не говорится в российской литературе, но из текста соответствующих правовых актов 
прямо вытекает, что независимость судебной власти в целом без подчинения закону не существует Именно подчинение закону обозначает зону независимости в смысле части 1 ст. 120 Конституции РФ ${ }^{20}$. Тогда элементами позитивной независимости судей следует считать все предписания, обеспечивающие свободу выбора при подчинении закону:

- права и обязанности, вытекающие из процессуального статуса и связанные с принятием решения;

- право на игнорирование указаний в непроцессуальной форме;

- право на судейское усмотрение;

- право на формулирование правоустанавливающих норм (Richterrecht), либо прецедентов в системе общего права;

- право на применение мер воздействия за нарушение порядка в судебном заседании.

Такая характеристика зоны независимости судей может вызвать серьезные возражения. В сущности, она отождествляет анализ судебной независимости с судебным правом и процессуальными порядками. Однако все предписания, регламентирующие позитивную зону ответственности, рассматриваются как описывающие потребности в независимости.

Так, по части 1 ст. 252 УПК РФ «Пределы судебного разбирательства»: «Судебное разбирательство проводится только в отношении обвиняемого и лишь по предъявленному ему обвинению». Следовательно, попытка расширить судебное следствие за пределы предъявленного обвинения устраняет независимость суда, хотя само по себе это должно быть выражено в процессуальном решении. Это же происходит в случае отвода судьи.

\section{Зона позитивной независимости как объект сравнительно-правового исследования.}

Здесь целесообразно выделить две группы элементов. Первая - предписания, устанавливающие конструкции, которые различно определяют границы зоны независимости. Вторая - нормы, устанавливающие различные последствия при посягательстве на независимость судей.

\footnotetext{
${ }^{20}$ Можно возразить, что судьи подчиняются закону во всей своей деятельности. Но это настолько очевидно, что такое общее понимание сделало бы саму конструкцию подчинения закону излишней. Однако она используется неукоснительно в законодательстве и РФ, и ФРГ. Это означает, что судья подчиняется закону, реализуя свою независимость. Он наделяется ею для подчинения закону.
}

Показательные примеры можно привести: первый - применение норм прецедентного права и статутного права и второй - нарушение независимости судей в состязательном и розыскном (инквизиционном) процессе.

Таким образом, анализ института независимости суда и судей в российской правовой системе должно основываться на результатах анализа регламентирующих его норм и учета их контекста. Оно не может ограничиваться гарантиями его институциональной и содержательной сторон. Обязательно следует изучать независимость судей как совокупности объективных и субъективных прав, дозволений, запретов, процедур и гарантий. При этом судебная независимость должна и впредь рассматриваться как принцип организации и деятельности судебной власти, ее краеугольный камень, составляющая права судебной власти или судебного права. Но этот вывод должен быть не априорным, а основываться на совокупности правовых норм, релевантных к праву независимости.

Это, во всяком случае, объясняется тем, что действию судебной независимости как принципа права, судебного права или же организации и деятельности судебной власти, т.е. как общего начала, должна предшествовать регламентация этого начала, определение его границ, регулятивности и пр.

Именно при анализе содержания независимости как состояния «для чего?» могут быть поняты реалии функционирования судебной власти и деятельности судей и собственно самого феномена независимости.

Независимость судей действительно определяет природу и состояние судебной власти. Наличие судебной независимости, её степень и содержание действительно отличает одну правовую систему от другой. На это обращается внимание применительно к различиям систем общего права и континентальной правовой семьи ${ }^{21}$.

Вместе с тем, хотя судебная независимость сама по себе определяет далеко не все в природе и содержании судебной власти, при надлежащем внимании можно обнаружить ее связи едва ли не с каждой нормой этой отрасли. Уже поэтому ее границы должны быть так определены, чтобы независимость не переходила в произвол.

Поэтому в целях сравнительного исследования судебной независимости необходим раздельный анализ отдельных групп самостоятельных норм, предназначенных именно и часто только для ее функционирования. Примером являются нормы, регулирующие доступ

\footnotetext{
${ }^{21}$ GG. Kommentator. Tubingen: Mohr Siebeck, 2000. S. 485-486
} 
DOI: $10.7256 / 1811-9018.2015 .5 .13917$

При цитировании этой статьи сноска на dоі обязательна

\section{Право и политика 5 (185) 2015}

к профессии судьи. Они могут и не быть связаны с состязательностью процесса, доступом к суду, справедливостью правосудия, не предопределяя общего состояния правосудия.

Наряду с этим, повторим, существует потребность в анализе с позиций системного подхода и топической логики института судебной независимости как правового института, определяющего содержание независимости, поскольку она бывает различной в национальных правовых системах и семьях права.

Необходимо уяснение оснований и границ права на независимость, а также выделение формальных и содержательных проблем судебной независимости, что требует рассмотрения ее с позиций аксиологического подхода, т.е. как социальной ценности, объективное содержание которой не вполне ясно, а субъективное крайне противоречиво.

Такое понимание судебной независимости позволит понять, какова она, в чем ее легитимность, представить ее как совокупность прав и обязанностей, обеспеченных определенными защитами. Для выполнения этой задачи следует обратиться к проблематике информации, характеризующей состояние судебной независимости в России, что в настоящее время не столь простая задача, несмотря на попытки проведения соответствующих исследований.

\section{Библиография:}

1. Алексеев С.С. Общая теория права. М.: Проспект, 2008.

2. Баранов В.М. Техника правотворчества. Природа. Основные приемы. Значение. М.: Юнити-Дана, Закон и право, 2010.

3. Сатаров Г.А., Римский В.Л., Благовещенский Ю.Н. «Социологическое исследование российской судебной власти»

4. Строгинович М.С. Курс советского уголовного процесса. М.: Изд-ва АН СССР, 1958. С. 111

\section{References (transliterated):}

1. Alekseev S.S. Obshchaya teoriya prava. M.: Prospekt, 2008.

2. Baranov V.M. Tekhnika pravotvorchestva. Priroda. Osnovnye priemy. Znachenie. M.: Yuniti-Dana, Zakon i pravo, 2010.

3. Satarov G.A., Rimskii V.L., Blagoveshchenskii Yu.N. «Sotsiologicheskoe issledovanie rossiiskoi sudebnoi vlasti»

4. Stroginovich M.S. Kurs sovetskogo ugolovnogo protsessa. M.: Izd-va AN SSSR, 1958. S. 111 